\title{
The role of social media platforms in increasing the efficiency of online communication activity
}

\author{
Anca Jarmila Guță* \\ University of Petroșani, Petrosani, University Street, Number 20, 332041, Romania
}

\begin{abstract}
Given the terms of the socia-media revolution that we pass, the goal of the paper is to identify the main types of social media platforms that contribute to increasing the efficiency in the online environment, where we work now. Starting from their characteristics we identified the degree of knowledge and use of main social media platforms in the current activity of a number of 39 teachers of the University of Petrosani who participated in a training course on e-learning platforms and online communication, a study that provided a realistic perspective on these issues.
\end{abstract}

\section{Introduction}

We are living a new revolution, in the true sense of the word. The reader becomes a producer of information, in a new public space, in which our perceptions of reality are radically changed, interpersonal relationships enter a new stage, multidimensional communication, and social interactions take place in a virtual world, which overlaps with the real one and hides it. It is the social media revolution, comparable, in terms of development and effects, to the Industrial Revolution, but it is much faster.

Virtual/online communities have become very popular in education because they encourage collaborative learning and teamwork. Training students in an online community allows both students and teachers to share their tacit knowledge and increase school performance. The virtual group community can be defined as a variable number of people who interact with each other, through specific social media, to achieve common goals. The term "virtual" emphasizes that the interaction between group members is not "face to face". Correspondence, telephone or the Internet are means of communication that allow community members to transcend geographical or political boundaries, with the aim of initiating and implementing common plans and projects. A very common type of virtual community is the online community. Recent advances in information and communication technology have been the main element that has determined the emergence and proliferation of this type of community.

The online community can be defined as that virtual community whose members communicate with each other through interactive tools, such as forums, chats, social networking sites or virtual worlds. Interactivity is the extent to which messages in a 
communication sequence are connected to each other and the degree to which subsequent messages are correlated with existing messages. This definition of interactivity recognizes three levels of communication:

$>$ bidirectional non-interactive communication - is present in the form of bilateral message flow;

$>$ reactive (or quasi-interactive) communication - occurs when there is bilateral flow, and subsequent messages refer to previous ones;

$>$ fully interactive communication - involves subsequent messages in any sequence to take into account not only the messages that preceded it, but more, how previous messages were reactive. This type of interactivity forms a social reality.

Because communication is computer-mediated, it is much easier to identify and count group interactions. At the same time, the emergence of virtual communities emphasizes the importance of human interactions.

In general, a community is based on the group. It must include persons who regularly communicate directly with each other, and their number must be limited so as to enable faceto-face communication. The development of new technologies has radically changed the meaning of the notion of group.

\section{Asynchronous online communication tools}

\section{E-mail}

Email continues to be the most popular tool for online communication. It allows groups of people to easily connect to communicate or exchange files. Specifically, contact lists are used for discussion groups and newsletters sent by the teacher to a group of student users.

Email is the simplest mechanism for direct one-to-one communication between teacher and student. Email is used to launch and answer individual questions, rather than answering questions of general interest. If the answer is optional and the topic is not of major importance, it is better to post the question on a forum.

\section{Newsletters}

Newsletters can be used to send a message to a group of students, for example to communicate to students the change of activities or an event (for example, urgent announcements concerning the whole class, upcoming tests, imminent deadlines, scheduling changes schedule). Only the teacher should send such messages and should not do so very often.

Contact lists can be used for discussions and document sharing between members of small groups (especially those with limited Internet access). They facilitate teamwork such as group projects and collaborative activities.

\section{Discussion forum}

Discussion forums are the main tool for online discussions. They allow a number of teachers and students to communicate by posting messages. In other words, participants can communicate at different times through written comments that remain on the forum so that other participants can read and respond to them. Each forum can contain one or more discussions, which consist of one or more messages and replies. In education, forums are used for discussions on specific topics, collaborative work on case studies, comments after class, etc. Also, both students and teachers can post or read messages and respond to them. Discussion forums are more suitable for large groups where participants are free to join common discussions by connecting to the learning platform (as an alternative to receiving more messages via email).

Wiki

A wiki is a website that can be edited online. Unlike regular web pages, which are created offline and then uploaded to a web server, wikis are edited in real time. Users do not need 
special technical knowledge to modify existing wiki pages or add new pages.

The administrator of a wiki can specify who can view and edit the site or its subsections. The administrator can also allow anyone to use and edit the wiki, or can restrict editing permissions to registered users. Teachers can use the wiki when they want students to work in teams on the same document or to exchange ideas and resources on a topic.

\section{Blog}

A blog (short for Web blog) is a tool that allows users to easily share, access, and update information without programming knowledge. Blogs were created to present content as a simple list of journal-like entries. A blog allows teachers and students to regularly post educational content online in a standardized format. The information posted forms a frequently updated comment or stream of ideas. The key element of a blog is that it allows the blogger (individual or group) to express their ideas, and to respond to other users through comments. Both blogs and wikis allow users to publish real-time web content through a web browser without their programming knowledge.

The difference between them consists in:

- blogs allow only a simple journal-like format;

- wikis do not require a specific web page structure and allow users to create new pages or edit existing ones.

In education, blogs make it easy to share, access and update information. Students can use them both to present their own options and to add comments on the posts of other participants. Participants can also use blogs as learning journals or as a place for reflection, brainstorming and short conversations. Blogs help students "understand" what they have learned.

\section{Webcasting}

The term "Webcasting" refers to audio and video files sent from a single source to multiple passive receivers. Typically, educational content is represented by a video lesson in which a teacher / expert speaks to several students at the same time, without interacting with them. Web and audio streaming devices are used for Internet transmission. However, recorded transmissions can also be used for asynchronous purposes.

\section{Podcasts}

Podcasts are audio programs that are broadcast on the Internet. They are audio files such as those in MP3 or wav format.

Video files can be used by the teacher to provide educational content (for example, short video lessons in which an expert gives a speech on a specific topic), motivation, or guidance. They can be used to show moving objects or processes (for example, the components of a machine), to introduce real people who speak (for example, native speakers can be introduced to an English language course) and to convey emotional messages.

Podcasts can be used by the teacher to provide guidance and motivation. Audio files can cover literacy gaps, and relatively small files are slightly easier to transmit in a smaller bandwidth than video files.

\section{Synchronous online communication tools}

\section{Chat and instant messaging}

Instant messaging is one of the most popular web applications. This allows multiple users to exchange real-time information in text format using a web or desktop application.

A group of users can start a conversation directly, using text, in a space usually called a "chat room." In a typical chat session, all users see the messages. However, some chats allow only certain members of the session to send messages.

Chat can be used as a communication channel for questions and answers during a 
presentation or meeting. Alternatively, the chat can be used for a separate event (for example, a study group meeting or role simulation). There are some tools with which teachers can create "stimulation sessions". This approach can be used to solve problems competitively, brainstorming, conducting debates with pros and cons or developing scenarios.

Chat sessions have the advantage of keeping the textual dialogue generated during a discussion.

Opinion polls

Teachers may ask students to answer an opinion poll, often in the form of a question with two or more possible answers. These surveys can be used by the teacher to collect students' opinions on certain course topics or to choose course activities.

\section{Audio and video conferences}

Audio and video conferencing are communication sessions that take place in real time between two or more users in different locations. They are mostly used for meetings of project members.

Some instant messaging applications can be incorporated into video chat applications. Voice over Internet Protocol (VoIP) applications and services allow users to make highquality calls using the Internet. One of the most popular programs that use VoIP is Skype. It allows you to make free calls to other Skype users and charges a small fee for calls made to regular phones. Phones provide higher audio quality and are more reliable; VoIP is cheaper and easier when it comes to communicating between multiple people in real time.

Audio conferencing can have wide applicability in e-learning and is suitable for course topics where the spoken-listening combination is crucial (language courses). Also, recorded audio conferences can be made available on the podcast and mimic the face-to-face experience and human presence. Video conferencing is especially suitable for training topics where visual clarity (medicine) is essential. These require very fast internet connections.

\section{Virtual classroom}

A virtual classroom mimics a traditional classroom, in the sense that it is led by a teacher by integrating different types of synchronous tools such as chat, audio conferencing or application sharing. Most virtual class-specific tools incorporate similar functions, although the screen interface may be different. Most of the screen serves as a blackboard, on which the teacher can design slides and students can write and drawMost virtual classspecific tools incorporate similar functions, although the screen interface may be different Most of the screen serves as a blackboard, on which the teacher can design slides and students can write and draw using text and drawing tools. On the left side of the screen, there is a participant window that shows the names of all those participating in the session, a set of tools to use for interaction (comparable to those of a traditional class, such as raising a hand or two fingers), the messaging window instant to send messages to other students or the instructor and the audio control of the microphone and speaker.

Each online community has its own characteristics. Goals vary, structures are different and people are different. But there are some common styles or patterns of participation that have been observed. Online communities depend on social interaction and the exchange of information between users. This interaction emphasizes the element of reciprocity in the unwritten social contract between community members.

\section{Social networks}

During the paper I will briefly present four social networks, considered representative that will be the subject of a question in the questionnaire that will be included in the paper on how to know and use by teachers who answered the questions in the questionnaire.

Facebook is a social networking site on the Internet, created by Mark Zuckerberg in 2004 to provide the opportunity to contact close people, but also people still unknown. At the 
moment, Facebook is one of the most widespread social networks in the world. Users can enter this network from anywhere where there is a password-based Internet access, initially set up by completing the registration form with a series of personal questions. Currently the facebook site has about 1.44 mild. members worldwide. Appreciated to be the second social site in the world after google.com, taken by the number of visits, facebook is part of the recent phenomenon called Web 2.0. Originally created at Harvard, USA, Facebook was originally a closed-loop social network for students at this university; later it opened to other American universities. At the beginning, the verification of belonging to the university was done through the student's e-mail address (e-mail), but starting with September 2006, the network is open to everyone. Immediately the Facebook network became very popular but also controversial, being banned in several countries in the Middle East.

Since its creation, Facebook has been the subject of controversy over users' privacy. The application uses the personal information of users in order to insert advertisements tailored to the profile of each user and even to sell this information to private companies, as mentioned in the facebook book on privacy. This book also indicates that Facebook may collect information about its members and from sources outside the network, such as newspapers, blogs or any other sources on the Internet. User information is collected by Facebook for the continuous improvement of its database and to allow its customers (payers) to address their advertising messages more successfully, knowing the consumer behavior of users. Thanks to Facebook ads, third-party sites can use the information gathered by Facebook to send targeted advertising based on the user's profile: these messages can make use of, for example, data about sex, level of education, political opinions, religion, places work or positions held by users. The strong point of Facebook is the large number of socialization possibilities accessible to any user (over 40,000 applications).

The most popular of these can be accessed right from the first page:

"Wall": is the section where the account owner can display public messages - visible to all users.

$>$ "Pokes": a way to alert another user, similar to the buzz in Yahoo! Messenger.

"Notes" (Notes): is an online text editor similar to the one on blogging platforms, which also allows uploading photos. Users can write extensive text, such as on a blogging platform, or they can import text written on blogs (WordPress, Xanga, Blogger or LiveJournal).

"Photos": the user can upload photos and arrange them in albums (service similar to Flickr). However, there is a quantitative restriction: an album cannot contain more than 200 images. Facebook offers an option that is not found elsewhere: tagging users directly on the photo, ie the tag (if a photo contains a friend's image, the user can tag it by typing his name, and he will receive a notification and a link to view the photo).

"Videos": Facebook allows you to upload videos with a maximum size of $1024 \mathrm{MB}$ and a duration of less than 20 minutes. There is also the option to upload videos recorded via the webcam (a service similar to that offered by YouTube).

$>$ News Feeds: Facebook has patented in the United States the news feed, respectively the display of a news feed within a social network, with links attached to the source of information, which also includes news about activities associated with a particular user in the social network environment. Thus, the news feed also contains important information about changes in friends' profiles, their birthdays or events that will take place in the near future, comments or links posted by users of a social network, according to the Facebook patent, approved by the American Office for Inventions and Trademarks. The method also includes limiting access to the news feed for a predetermined number of other users, sorting the news feed, and 
displaying the news in the order assigned to at least one reader in the user list. In this way, Facebook has become the legal owner of a vital invention for its main competitors, Twitter, Myspace and Google, and has the opportunity to sue companies that use news feed applications that fall within the description of the patent. The Twitter platform is mainly targeted, whose users create millions of pieces of information on a news structure every day.

$>$ Chat: is an instant communication service (such as Yahoo! Messenger), which allows discussions with other Facebook users, both in the form of interpersonal communication and in a conference system.

$>\quad$ "Events" (Events): Facebook members can notify their friends about the imminence of events and can send invitations, with the form to deny / confirm participation - a service widely used by those in PR to organize events.

"Games" (Games): one of the reasons that led to the popularity of Facebook are games that facilitate social interactions between users and greatly increase the time they spend on the platform (which leads to increased advertising revenue). For example, FarmVille, which is played daily by more than 300 million people (it also won the Social Game of the Year award), provides a great virtual setting for initiating online interactions (the game recreates the countryside, where everyone can create a farm, to raise animals, etc.). Thus, it is much easier to approach Andi Moisescu, for example, if he is your farm neighbor and you harvest wheat from two neighboring fields, than if you should approach him in real life.

$>$ Another game that is beginning to surpass FarmVille in popularity is CityVille. "Ads" (Marketplace): Facebook users have the opportunity to display free advertisements in the categories: "For sale", "Housing", "Jobs" and "Other". In 2009, Facebook transferred ownership of Marketplace to Oodle.com. The secret to good privacy management on Facebook is the ability of each user to determine the extent to which they want people to know about it and / or its activities and the degree of interaction with them. From here, an informed user can choose his own level of privacy, according to his preferences. Instead, a less informed user may fall prey to risks such as inadvertent disclosure of personal profile information or breach of privacy (through photos, videos, comments, etc.). However, within the social network Facebook there are also groups of users who act against the violation of their privacy (for example: "Damn, Facebook, Stop Stalking Me Group" or "STOP! Do not get into my private life. No personal questions!! Grouse The way people meet has been influenced by the scale of the Facebook phenomenon. Thanks to this social network we can invite or can be invited to various events, from birthdays or business meetings to weddings and other large social events or business meetings. The advantage is that invitations can be sent to a large number of people, including people who could not have been invited otherwise. Now we can participate in events that we would not have known otherwise.

Instagram is an online photo-sharing, video-sharing, and social networking service that gives users the ability to upload photos and videos, apply digital filters, and share them on a variety of social networks, such as Facebook, Twitter, Tumblr and Flickr.

Instagram was created by Kevin Systrom and Mike Krieger, and was launched in October 2010. The service quickly gained popularity in April 2012, reaching 100 million registered users. Instagram is distributed through the App Store, Google Play and Windows Phone Store. The service was purchased by Facebook in April 2012 for approximately $\$ 1$ billion. In 2013 , Instagram grew by $23 \%$, while Facebook, the parent company, by only $3 \%$.

Instagram is one of the most used social networks in communicating companies with consumers. According to published data, there are 25 million business accounts on Instagram, and over $80 \%$ of Instagram users in the world follow a business account. 
About Instagram we can clearly say that in 8 years it has become an unattainable force among social media platforms on the global market. As a site, Instagram was listed as one of the most popular in the world, ranking 21 st in the US and 41 st globally, according to popularity. It started to have the highest market penetration rate, however, starting with 2012, when Facebook put a sum of nine zeros on the table, ie about one billion dollars.

Today, Instagram has an estimated market share of $\$ 100$ billion. But, no matter how hard you try, you will never know everything about Instagram or be able to write a single article in which to explain everything, because you will most likely end up writing over 25,000 words.

Like other social networks, Instagram has the fundamental role of bringing together people with common interests in one place. In other words, you create an account, configure it and start looking for users who have common interests with you. In this step, there are two objectives to be achieved:

- Follow people with the same interests as you;

- Make these people follow you, in turn.

If you do not want your profile to be viewed by anyone, you can set your profile to private. This also gives you advantages. One of them is that if someone wants to view your profile, they will have to add you to their list of followers. This way, over time, your list of followers will grow. A disadvantage of your private profile is that you will use hashtags in vain in posts, because they will not be displayed on the trending / public / explore page or for any of the hashtags. used.

Instagram is now available on all Android and iOS mobile devices, tablets and PCs. On the desktop version, however, Instagram has some limitations, unlike the mobile application. The major difference between a desktop and a mobile application is that you can't edit or post photos / videos from your computer - you can just look at pictures, like and comment, or access the main newsfeed.

LinkedIn is a business-oriented social network. It was founded and started operating in 2003. The social network does not publish its financial results and earns revenue from advertising and premium services. The company has been listed on the stock exchange since May 19, 2011, under the symbol LNKD, at which time the market value of the company was $\$ 4.25$ billion.

The company's total revenue was \$ 522 million in 2011, compared to \$243 million in 2010. Over 400,000 employees in Romania have profiles on LinkedIn. In 2016, Microsoft bought LinkedIn for $\$ 26$ billion. Those who open an account on LinkedIn can make their $\mathrm{CV}$ public (either fill it in online or import it), search for jobs or share opinions and materials in the feed, just like on Facebook. At the same time, users can interact with company representatives when new job opportunities arise. Or with colleagues and friends who already have accounts. In Romania, over 1.7 million Romanians have a profile on LinkedIn. Statistics say that every second, two people sign up on this social network. In addition to other social networks, LinkedIn offers the opportunity to those who have an account to recommend the strengths of the people they have worked with or are collaborating with.

According to The Sophisticated Marketer Guide to LinkedIn and data published by LinkedIn.com for 2017, here's how important the LinkedIn profile is:

$\checkmark \quad$ One in three professionals on the planet is on LinkedIn.

$\checkmark \quad 50 \%$ of LinkedIn members say they are more willing to buy from a company that is on LinkedIn.

$\checkmark \quad 80 \%$ of LinkedIn members want to connect with certain companies to facilitate their decision-making process.

$\checkmark \quad 91 \%$ of online marketers say that LinkedIn is the number 1 channel to distribute content. 
$\checkmark \quad 93 \%$ of B2B marketers believe that LinkedIn is the most efficient online network for lead generation, much more efficient than Facebook and Twitter LinkedIn directs more traffic to company blogs and sites than Twitter, Facebook and Google+.

$\checkmark \quad 51 \%$ of companies attract customers through LinkedIn.

$\checkmark \quad 65 \%$ of journalists use the information on LinkedIn to write articles. Therefore, it is recommended that the profile of a company be transparent, to present information about its activity, about customers, shareholders, figures about the company.

$\checkmark \quad 64 \%$ of LinkedIn users are from outside the United States.

$\checkmark \quad$ Only $42 \%$ of users update their profile regularly.

$\checkmark \quad 35 \%$ of users access LinkedIn every day.

$\checkmark \quad 39 \%$ of LinkedIn members pay for services on this professional network.

$\checkmark \quad$ There are over 3 million company pages on LinkedIn.

$\checkmark \quad$ Today, LinkedIn gains 1 million new users every 12 days or 2 users every second.

LinkedIn can be perceived as a "professional Facebook". According to statistics, more than half of Romanian recruiters or employers check the LinkedIn profiles of candidates. However, most of the LinkedIn profiles of Romanian users are usually out of date or incomplete. Such a profile is not relevant to an employer or a potential business partner. LinkedIn is a platform that hosts online resumes, a job search engine, but also a professional social network. A valuable profile means a professional image.

ResearchGate is a social networking site for scientists and researchers to share papers, ask questions and answer questions and find collaborators. While reading articles does not require registration, people who want to become members of the site must have an email address at a recognized institution or be manually confirmed as a published researcher to sign up for an account. Users can also follow the activities of other users and have discussions with them. Users can also block interactions with other users.

The site has been criticized for sending unsolicited e-mail invitations to co-authors of articles listed on the site that were written to appear as if e-mails were sent by other coauthors of the articles (a practice that $\mathrm{ul}$ stated that it has discontinued it since November 2016) and for the automatic generation of apparent profiles for users who sometimes did not feel wrong. One study found that more than half of the uploaded articles appear to infringe copyright because the authors uploaded the publisher's version.

Site members may "follow" a research interest, in addition to following other individual members. It has a blogging feature for users to write short reviews on peer-reviewed articles. ResearchGate indexes information posted on its own profiles to suggest members connect with others who have similar interests. When a member answers a question, he or she addresses other people who have identified in the user profile that they have relevant experience. It also has private chat rooms, where users can share data, edit shared documents or discuss confidential topics. The site also has a research-focused job board.

As of 2018, it has more than 15 million users, with the largest user bases coming from Europe and North America. Most ResearchGate users are involved in medicine or biology, although it also has participants in the fields of engineering, computer science, agricultural sciences and psychology, among others.

\section{Study about the degree of using the different online communities in the university background}

The questionnaire proposed to the 39 responding teachers, teachers who were part of the target group of the POCU project - Education a chance for the Jiu Valley and who completed a postgraduate course in the project in which they studied a discipline of online communities is next:

1) Based on a recent study, it was found that social media platforms in Romania have 
a traffic three times higher than the sites of newspapers or news televisions. From your point of view, do you consider the presence on social media platforms useful in your current activity?

YES

NOT

2) What asynchronous online communication tools do you already use?

E-mail

Discussion forum

Newsletters

Blog

Podcast, vodcast

3) Which of the synchronous online communication tools do you consider useful in the activity you carry out?

Chat and instant messaging

Opinion polls

Audio and video conferences

Virtual classroom

4) Which of the social networks do you already have an account for?

Facebook

Instagram

Linkedin

Researches gates

5) Do you think it would be to your advantage to enrich your knowledge of the main social media platforms?

YES

NOT

\section{Interpretation of the questionnaire}

1) To the question no. 1 of the questionnaire "Based on a recent study, it was found that social media platforms in Romania have a traffic three times higher than the sites of newspapers or news televisions. From your point of view, do you consider that your presence on social media platforms is useful in your current activity? all members of the target group rejected in the affirmative.

2) The answers to question no. 2 of the questionnaire are summarized in the figure below:

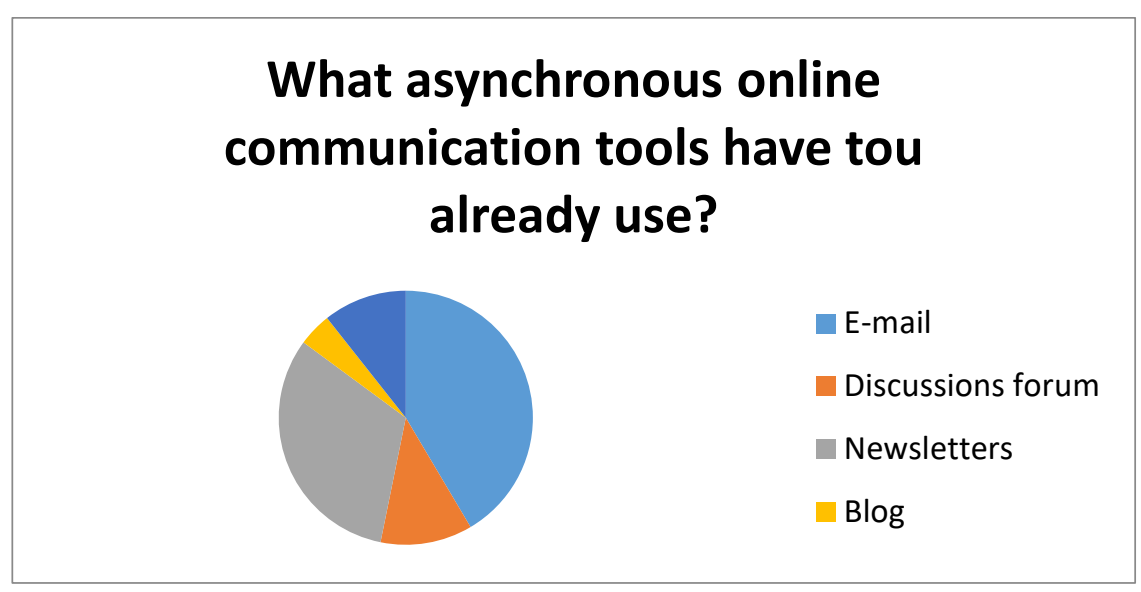

Therefore, the most used asynchronous online communication tools are e-mail and newsletters, and on the other hand, the least used are podacasts, vodcasts and blogs.

3) The answers to question no. 3 of the questionnaire are summarized in the figure below: 


\section{Which of the synchronous online communication tools do you consider to be useful in the activity that you carry out?}

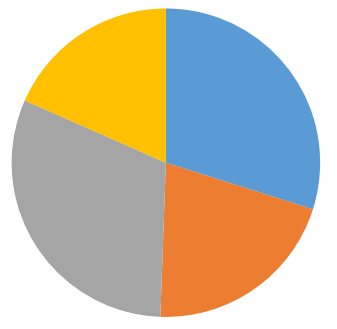

Chat and instant messages

Opinion polls

Audio and video conferences

Based on the above, it can be seen that audio and video conferencing (27 respondents) and online chat and messaging (26 respondents) occupy relatively equal places as synchronous online communication tools used in the activity of members. target group. Opinion polls (18 respondents) and the virtual classroom (16 respondents) also occupy a relatively equal proportion in the preferences of the members of the target group, but the number of those who use them is lower than the first two categories of synchronous online communication tools.

4) The answers to question no. 4 of the questionnaire are summarized in the figure below:

\section{Which social media platform do you already have on account?}

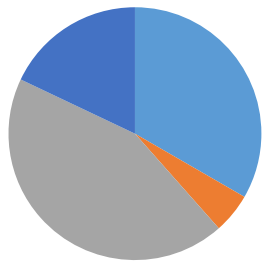

Facebook
Instagram
Linkedin
Researches gates

Based on the above figure, it appears that most of the accounts held by the members of the target group are on Linkedin (34), followed by the social network Facebook (26), Researches gates (14) and Instagram (4). Analyzing these data, it can be concluded that the members of the target group prefer the social networks Linkedin and Facebook, and the Researches gates network, which is mainly for researchers, is less used or known by them, which is why it is beneficial to present it to target group members. The fact that the social network Instagram is used by very few members leads us to the conclusion that it should be presented more in the classes of this discipline.

5) To the question no. 5 of the questionnaire "Do you think it would be to your advantage to enrich your knowledge regarding the main social media platforms?" all 39 members of the target group surveyed answered in the affirmative, which implies a special interest given by the surveyed teachers regarding the online communication environment.

A main conclusion of this paper is the interest that shown by the participants in the study on knowledge of social media platforms and the online communication environment in 
general, which proved to be extremely beneficial during the academic year that just followed the study, in terms of the transition from classical education, face to face to online education. I believe that the participants in the study improved their skills and abilities regarding the online environment, managing to better cope with the challenge we were all subjected to in terms of the period we are going through, a period that completely changed the paradigm of education.

\section{References}

1. Badea E., Badea A. Platforme de e-learning (Moodle), Revista New Projects, mai, (2017)

2. Balaban, D., Comunicare mediatică, Editura Tritonic, Bucureşti, (2009)

3. Bădău H. M., Tehnici de comunicare în social-media, Editura Polirom, (2011)

4. Bărbieru, D. I., Şuşnea, E., Crăciun, M., Comunităţi virtuale pentru cercetare, dezvoltare, inovare, Managementul cunoaşterii în universitatea modernă, Editura ASE, Bucureşti, (2007)

5. Ghilic-Micu B., Stoica M., Economia digitală şi societatea bazată pe informație şi cunoaştere, în volumul Societatea cunoaşterii, coord. Roşca Gh.I., Editura Economică, Bucureşti, (2006)

6. Joannes, A., Comunicarea prin imagini, traducere de Ioana Manole, Editura Polirom, (2009)

7. Jongseok S., Lidziya L., Young-Seok O., Dongphil C. Priorities of Coworking Space Operation Based on Comparison of the Hosts and Users' Perspectives, Sustainability, 9(8), (2017)

8. Krosseck G., Marketing si comunicare pe internet, Editura Lumen, București, (2012)

9. Mazili C. - Necesitatea utilizării reţelelor sociale, Web Marketing PCG, februarie, (2011)

10. Petrescu, A., Blogul, instrument de relaţii publice şi marketing online, în PR, Publicitate şi NewMedia, coordonatori Delia Cristina Balaban, Ioana Iancu, Radu Meza, Editura Tritonic, Bucureşti, (2009)

11. Popescu M. Site-ul web: Între modalitate de comunicare şi instrument strategic de marketing, Revista de Marketing Online - Vol.2, Nr. 1, (2017)

12. Şuşnea E., Instruire asistată de calculator, Editura Universității Naționale de Apărare "Carol I", București, (2013)

13. http://blog.kissmetrics.com/facebook-statistics/?wide=1

14. http://n2n.ro/retele-sociale/statistica-surprinzatoarea-a-zilei-facebook-vs-twitter/

15. http://ro-ro.facebook.com/note.php?note_id=104072202976460http://economie.hotnews.ro/stirimedia_publicitate-8271567-cat-importante-sunt-retelele-sociale-revoltele-

16. https://ro.wikipedia.org/wiki/Instagram

17. https://stoianciprian.blog/totul-despre-instagram/

18. https://ro.wikipedia.org/wiki/LinkedIn

19. http://train2perform.eu/4/evenimente/42/articole-hr/32/cum-sa-iti-gestionezi-profilul-de-linkedinsi-la-ce-te-poate-ajuta.html

20. https://help.pinterest.com/ro/guide/all-about-pinterest

21.https://www.nature.com/news/publishers-threaten-to-remove-millions-of-papers-fromresearchgate 1.22793

22. https://gatesopenresearch.org/ 